\title{
The Comparison of the Polyeythlene Wear Rates in Hybrid and Uncemented Total Hip Arthroplasty with Stem as a Variant at 8 to 10 Yrs mid Term Follow Up
}

\author{
Piyush Mukund ${ }^{1}$, Won Yong Shon ${ }^{1}$, Sang-Min Kim² and Lokesh Gudda Naik*1 \\ ${ }^{1}$ Department of Arthroplasty, Korea University Guro Hospital, South Korea
}

${ }^{2}$ Department of Orthopaedics, Korea University and Medical Center, South Korea

Received: February 14, 2018; Published: February 21, 2018

*Corresponding author: Lokesh Gudda Naik, Fellow in Arthroplasty and Revision Arthroplasty, Under Professor Won Yong Shon, Department of Arthroplasty, Korea university Guro Hospital, Seoul, South Korea, Clinical Associate, Department of Orthopaedics, Sir HN Reliance Foundation Hopsital, Mumbai, India, Tel: 9987685708; Email: drortholokesh@gmail.com

\begin{abstract}
Polyethylene wear in both cemented and uncemented total hip arthroplasty (THA) lead to generation of particles with their access to the interface which has been responsible for periprosthetic osteolysis and subsequent loosening of cup and stem. Many studies have been published studying the pattern of polyethylene wear and its relation to the type of implant (cemented/ uncemented cup or ceramic/metal head) used. No study in our knowledge has strictly focused on the effect of cemented versus uncemented stem on the polyethylene wear rates. We tried to compare the polyethylene wear rates reckoned with software (Poly Ware REV 7) of ultra high molecular weight polyethylene (UHMWPE) in hybrid and uncemented THA and its effect on complications of total hip replacements. We retrospectively reviewed pre-matched 56 patients in uncemented group with 112 patients in hybrid group on the basis of polyethylene wear rate, revision rates and clinical issues, with mean follow up of 9.42 and 7.25 years (yrs.) respectively.

Mean polyethylene wear rate in uncemented group was 0.048 milli metres per year (mm/yr.) and it was $0.082 \mathrm{~mm} / \mathrm{yr}$. in hybrid. Wear rate in hybrid group ceramic head $(0.072 \mathrm{~mm} / \mathrm{yr}$.) was significant when compared to wear rate ceramic head in uncemented group (0.053mm/yr.), also we found significant difference of poly wear in the metallic group as well. There was no difference in stem loosening and cup osteolysis in low wear (<.05 mm/yr.) and high wear group ( $>.05 \mathrm{~mm} / \mathrm{yr}$.) in both uncemented and hybrid THA. The revision was significantly higher in uncemented group but when adjusted with the age, it is equivocal. We found significant difference in polyethylene wear rates, but no significant difference in clinical performance and revisions among the two groups of uncemented THA and hybrid THA when compared on a mid-term 8 to 10 yrs. Follow up.
\end{abstract}

Keywords: Total Hip Arthroplasty; Polywear; Uncemented THA; Hybrid THA

Abbreviations: THA: Total Hip Arthroplasty; UHMWPE: Ultra High Molecular Weight Poly Ethylene; Yrs: Years; Mm/yr: Millimetres per year; PACS: Picture Archiving and Communication System; HHS: Harris Hip Scores; LLD: Limb Length Discrepancy

\section{Introduction}

Aseptic loosening has proven to be a major cause of failure of Total hip arthroplasty since its introduction in the late 1960s. Efforts to reduce component loosening rates have included alteration in component design and materials, use of porous coated cementless fixation of cup and stem, and modifications in bone preparation and cementing methods [1]. Uncemented THA and hybrid prosthesis have been the preferable choice of fixation recently which is supported by perceived higher rates of failure of cemented THA in longer terms especially in younger patients [2,3]. Clinical success and longevity of the THA prosthesis depends on the achievement of long term implant component fixation, maintenance of structural integrity and avoidance of aseptic loosening and osteolysis [4]. Periprosthetic osteolysis has been one of the most common complication and leading cause of revision after primary THA [5]. The biological consequences of polyethylene wear in both cemented and uncemented THA leading to generation of particles and their access to the interface has been proved which further causes osteolysis and been responsible for high rates of failure $[6,7]$.

Hence polyethylene wear is the predominant factor leading to periprosthetic osteolysisand loosening of the implant with higher 
rates of failure [8-11]. Polyethylene wear has also been responsible for causing late instability of the hips causing dislocations and revisions [12]. Many studies have discussed the controversial comparison of cemented and uncemented acetabular components effect on polyethylene wear rates with some studies showing lower wear rates in cemented THA $[13,14]$ and some studies showing no difference in cemented and uncemented acetabular components[15,16]. No study in our knowledge has strictly focused on the effect of stem on the polyethylene wear rates. Keeping all the facts the purpose of our study is to evaluate the effect of cemented and uncemented stem as a variant on UHMWPE wear rates and its influence on interface leading to stem loosening, clinical outcome, revisions and complications in uncemented and hybrid THA.

Table 1: Patient Pre Operative Demographic and Function.

\begin{tabular}{|c|c|c|c|c|c|c|}
\hline \multicolumn{2}{|c|}{ Parameters } & \multicolumn{2}{|c|}{$\begin{array}{c}\text { Hybrid Total Hip } \\
\text { Replacement(n=112) }\end{array}$} & \multicolumn{2}{|c|}{$\begin{array}{l}\text { Uncemented Total Hip } \\
\text { Replacement(n=56) }\end{array}$} & P-value \\
\hline \multicolumn{2}{|c|}{ Sex: Male/Female } & 52 & 40 & 38 & 18 & 0.171 \\
\hline \multicolumn{2}{|c|}{ Percentage } & $56.52 \%$ & $43.48 \%$ & $67.86 \%$ & $32.14 \%$ & \\
\hline \multirow{2}{*}{\multicolumn{2}{|c|}{$\begin{array}{c}\text { Mean Age in years } \\
\text { Range }\end{array}$}} & \multirow{2}{*}{\multicolumn{2}{|c|}{$\begin{array}{l}54.6 \pm 12.05 \\
25-74 \text { years }\end{array}$}} & \multirow{2}{*}{\multicolumn{2}{|c|}{$\begin{array}{c}46.13 \pm 09.73 \\
22-58 \text { years }\end{array}$}} & 0.0001 \\
\hline & & & & & & \\
\hline \multicolumn{2}{|c|}{ Mean Follow up } & \multicolumn{2}{|c|}{$9.42 \pm 2.44$ years } & \multicolumn{2}{|c|}{$7.25 \pm 1.64$ Years } & 0.0001 \\
\hline \multicolumn{2}{|c|}{ Mean Weight in Kilograms } & \multicolumn{2}{|c|}{$62.4 \pm 9.56$} & \multicolumn{2}{|c|}{$60.6 \pm 8.98$} & 0.243 \\
\hline \multirow{5}{*}{ Diagnosis } & ONFH with Secondary OA & \multicolumn{2}{|c|}{$101(90.17 \%)$} & \multicolumn{2}{|c|}{$45(80.35 \%)$} & 0.635 \\
\hline & Dysplastic Hips & \multicolumn{2}{|c|}{0} & & \\
\hline & Post Traumatic Hips & \multirow{2}{*}{\multicolumn{2}{|c|}{$\begin{array}{c}0 \\
004(3.58 \%)\end{array}$}} & & & \\
\hline & Septic Sequelae & & & \multicolumn{2}{|c|}{$07(12.50 \%)$} & 0.041 \\
\hline & Inflammatory Arthritis & \multicolumn{2}{|c|}{$007(6.25)$} & \multicolumn{2}{|c|}{$04(7.15 \%)$} & 0.837 \\
\hline \multicolumn{2}{|c|}{ Preoperative Harris Hip Score } & \multicolumn{2}{|c|}{$69.72 \pm 4.63$} & \multicolumn{2}{|c|}{$68.93 \pm 5.56$} & 0.332 \\
\hline \multirow{2}{*}{ Liner } & Standard Liner & \multirow{2}{*}{\multicolumn{2}{|c|}{$\begin{array}{l}81 \\
31\end{array}$}} & \multirow{2}{*}{\multicolumn{2}{|c|}{$\begin{array}{l}46 \\
10\end{array}$}} & 0.606 \\
\hline & Elevated Liner & & & & & 0.269 \\
\hline
\end{tabular}

\section{Materials}

After obtaining ratification from the IRB, we retrospectively reviewed all the patients who underwent uncemented or hybrid THA between 1999 to 2008 following strict exclusion criteria of revision cases, patients lost to follow up and patients with follow up less than 4 years. All the patients were matched for preoperative demographic factors except for age which could not be matched. 56 patients were in uncemented group, with 38 males and 18 females, the mean age was 46.13 (ranging from 22-58). Of the 92 patients (112 hips) in hybrid group with 52 males and 40 females, the mean age was 54.6 (ranging from 25-74) (Table 1). All the cases were operated by same senior surgeon using postero-lateral approach with standard postoperative rehabilitation programme. Uncemented THA received Zimmer uncemented triology cup and versus midcourt stem. Hybrid THA received Zimmer uncemented trilogy cup and cemented Versys heritage (V/H) stem. Modern cementing techniques with lavage and pressurization with cement gun was used in each hybrid case.

All the cases had ultra high molecular weight polyethylene as the liner (UHMWPE) with $28 \mathrm{~mm}$ head size in both ceramic as well as metallic head. The effect of liner thickness and acetabular cup positioning on wear rates has been negated in view of randomization as all the cases being done by the same surgeon in both the groups and in view of recent studies $[17,18]$. Patients were followed up radiologically and clinically at each follow up with mean follow up of 7.25 years for uncemented group and 9.42 years for hybrid group. The decision for the uncemented and revision hybrid THA was not random in lieu taken on the basis of preoperative planning considering bone stock, type of femoral stem (Dorr classification of proximal femur) [19] and Intraoperative assessment of the stem fixation. Polyethylene wear was assessed at each follow up using Poly Ware software (Poly Ware REV 7). All the values were taken twice at each follow up by two individual and at two weeks interval to negate the effect of inter-observer and intra-observer variation and wear rates calculated with the average of final values at the final follow up.

Digitalized images of all radiographs were acquired using a picture archiving and communication system (PACS) (Infinite, Seoul, South Korea). Osteolysis was assessed on the most recent AP and lateral films by the presence of lucent lines as described by DeLee and Charnley for cup and Gruen, McNeice and Amstutz [20] for the stem. Results were assessed on the basis of final follow up acetabular liner wear in ceramic or metallic head and hence calculated wear rate for both the groups effecting the stem interface, Harris hip scores (HHS), revision rates, and complications. Radiological assessment was done for loosening of stem Barracks cement grading [21], Harris criteria of loosening [22], cup migration and cup osteolysis. All the statistics were calculated using SPSS software, version 20.0 [Chicago, IL, USA]. Results were appraised and compared between two groups with null hypothesis with significance $\mathrm{p}<0.05$. chi-square test used for 
categorical variables. Multiple regression analysis was applied for the poly wear rate comparison to negate the effect of confounding variables which could not be pre-matched.

\section{Results}

Patients in both the groups were pre-matched for the confounding factors except for the age as the decision was clearly based on the previous studies with hybrid THA in older patients as compared to younger for uncemented THA. There were no intraoperative complications like iatrogenic fractures in uncemented and pulmonary embolism in cemented group with no perioperative death. The revisions, the cases lost to follow up and the cases with follow up less than 4 years were excluded from the study.

\section{Rates of Wear}

Cup Osteolysis and stem loosening: The mean rates of wear in hybrid group THA was $0.082 \mathrm{~mm} / \mathrm{yr}$. as compared to $0.048 \mathrm{~mm} /$ yr. in uncemented group patients. Polyethylene wear rates in uncemented group were compared with hybrid group with respect to ceramic and metallic heads in both the groups. It was found that polyethylene wear rates in ceramic head was more in hybrid group (0.072) as compared to uncemented group (0.053) $(\mathrm{p}=<0.0001)$ and was statistically significant (Table 2-4).

Table 2: Comparison of Results between Hybrid and Uncemented Total Hip Replacement

\begin{tabular}{|c|c|c|c|}
\hline Parameters & $\begin{array}{c}\text { Hybrid Total Hip } \\
\text { Replacement(n=112) }\end{array}$ & $\begin{array}{c}\text { Uncemented Total Hip } \\
\text { Replacement(n=56) }\end{array}$ & P- Value \\
\hline Post operative Harris Hip Score & $92.1 \pm 6.71$ & $92.36 \pm 6.17$ & 0.83 \\
\hline Revision rate(Percentage) & $1(1.78 \%)$ & $3(8.92 \%)$ & 0.08 \\
\hline $\begin{array}{c}\text { Average Liner Wear rate(millimeter } \\
\text { per year) POLYWARE }\end{array}$ & $0.082 \pm 0.024$ & $0.048 \pm 0.018$ & $<0.0001$ \\
\hline
\end{tabular}

Table 3: Comparison of Complications between Hybrid and Uncemented Total Hip Replacement.

\begin{tabular}{|c|c|c|c|}
\hline Complications & $\begin{array}{c}\text { Hybrid Total Hip } \\
\text { Replacement(n=112) }\end{array}$ & $\begin{array}{c}\text { Uncemented Total Hip } \\
\text { Replacement(n=56) }\end{array}$ & P- Value \\
\hline Infection (Percentage) & $1(0.89 \%)$ & $2(3.57 \%)$ & 0.227 \\
\hline Dislocation (Percentage) & $1(0.89 \%)$ & $1(1.78 \%)$ & 0.620 \\
\hline $\begin{array}{c}\text { Limb Length Discrepancy } \\
\text { (Percentage) }\end{array}$ & 00 & $1(1.78 \%)$ & 0.160 \\
\hline $\begin{array}{c}\text { Heterotopic Ossification } \\
\text { (Percentage) }\end{array}$ & $16(14.2 \%)$ & $6(10.71 \%)$ & -- \\
\hline Cup Migration (Percentage) & 00 & 0 & -- \\
\hline Stem Loosening (Percentage) & 00 & 0 & 0.569 \\
\hline
\end{tabular}

Table 4: Polyethylene Wear Comparison in Hybrid and Uncemented Total Hip Replacement.

\begin{tabular}{|c|c|c|c|c|c|}
\hline Prosthetic Head Used & \multicolumn{2}{|c|}{ Hybrid Total Hip Replacement(n=112) } & Uncemented Total Hip Replacement(n=56) & P-Value \\
\hline \multirow{2}{*}{ Ceramic } & Number & Wear & Number & Wear & 0.0001 \\
\cline { 2 - 6 } & 008 & $0.072 \pm 0.08$ & 032 & $0.053 \pm 0.0164$ & Wear \\
\hline \multirow{2}{*}{ Metallic } & Number & Wear & Number & 0.0001 \\
\cline { 2 - 6 } & 104 & $0.092 \pm 0.034$ & 024 & $0.039 \pm 0.017$ \\
\hline
\end{tabular}

Harris hip scores were recorded at each follow up and final Harris hip scores were compared in both the groups. The preoperative HHS in uncemented and hybrid THA was 68.93 and 69.72 respectively. Mean last follow up Harris hip score in hybrid group was 92.1 and in uncemented group was 92.36 with no significant difference in both groups (Tables 1 \& 3).

\section{Revision}

Both the groups were compared with respect to the revisions with hybrid group having 1 (1.78\%) and uncemented group having 3 revision surgeries (8.92\%). Revision in hybrid group was due to infection. Out of 3 revisions in uncemented group, one each for LLD, infection and recurrent dislocation whereas 1patients had reoperation for acute infection for which surgical debridement was done. When adjusted with age we did not find any significant difference between the two revision rates (Tables $2 \& 3$ ).

\section{Complications}

Both the groups were compared with respect to complications like infection, dislocation, limb length discrepancy, heterotopic ossification, cup migration and stem loosening. There was one case of infection $(0.89 \%)$ in hybrid and two cases in uncemented (3.57\%). There was one case of dislocation in both the groups. One case of limb length discrepancy (1.78\%) whereas no such case was present in hybrid group. 16 cases (14.2\%) were present for heterotopic ossificans in hybrid group and $6(10.71 \%)$ were present in uncemented group. No significant difference was found for any of these complications (Table 2). 


\section{Discussion}

In this retrospective study we tried to compare the polyethylene wear rates in both the groups of uncemented THA and hybrid THA. Onsten et al. [23] and Stambough et al. [24] in their studies have shown the trend of decreasing wear rates with time. Polyethylene wear rates in uncemented group were $.05 \mathrm{~mm} / \mathrm{yr}$. Perez et al. [25] and Berger et al. [26] have shown the wear rate of $0.25 \mathrm{~mm} / \mathrm{yr}$. And $0.16 \mathrm{~mm} / \mathrm{yr}$. in uncemented THA. The high average wear rate in these studies as compared to ours can be accounted for the younger population and comparatively shorter follow up in these studies. Polyethylene wear in hybrid group was $0.145 \mathrm{~mm} / \mathrm{yr}$. We did not find any long term follow up study about polyethylene wear rates in hybrid THA except for study by Poole et al. [27] and Hernandez et al. [28]. They have shown wear rate of $0.173 \mathrm{~mm} / \mathrm{yr}$ and $0.15 \mathrm{~mm} /$ yr respectively. In a recent review of literature by Dumbleton et al. [4] it was predicted that wear rates $>0.1 \mathrm{~mm} / \mathrm{yr}$ is shown to have greater risk of osteolysis and eventual loosening.

In our study we found there is no significant correlation between stem loosening and cup osteolysis with wear rates in both hybrid as well as uncemented THA. Sochart et al. [6] and Barrack et al. [29] have shown increased loosening rates of Charnley type prosthesis and cup osteolysis respectively with increasing wear. The difference in the results can be attributed to the lower overall wear rates in our study and the fact that we did not encounter any case of significant implant loosening in our study groups. The mean wear rates in hybrid THA in ceramic on polyethylene cases are higher when compared to ceramic on polyethylene cases in uncemented THA. Hernandez et al. [28] have shown the hybrid wear rates of $0.15 \mathrm{~mm} / \mathrm{yr}$ which is lower as compared to $0.22 \mathrm{~mm} /$ yr in uncemented THA. Hernandez et al. [28] also show that the cement may help to absorb some of the stresses, and thus reduce the forces within the polyethylene initially but with the mid to long term follow up, this effect seems to nullify.

The same finding was also confirmed by Hartofilakidis et al. [15] in their study. We did not find any other study in literature for comparison but higher mean rates in hybrid THA in our study can be construed for the haphazard distribution of cases with lower number of ceramic head cases in hybrid group. Revisions in uncemented hips were significant as compared to hybrid THA but not significant when adjusted to the age which seems to be the playing confounding variable here. A study by Hooper et al. [30], the authors found lower overall revision rates of hybrid when compared to uncemented. Our results were similar to the study by McMinn et al. [31] as he also suspected the possibility of confounding variable present in his study. Good mid to long term results and outcomes have already been proved for hybrid THA. [32-34]. Though short term studies have shown hybrid THA better than uncemented THA in clinical perspective but we did not find any significant difference in both the groups clinically on the basis of HHS comparison in our study.

There are several limitations in our study. First of all, being a retrospective study design, it is never as ideal as randomized controlled trial. The number of cases in hybrid group outweighs the number of case in uncemented group. We could not match the age although we reckoned and construed on the adjusted values only. Also the activity of the patients have been matched by pre HHS, we believe the results are not affected by this factor. We did not have enough chronological year wise follow up data of all the cases to comment on the pattern of the wear with respect to time. Possibility of type 1 error should be speculated always before any consideration. The strength of our study includes strict patient inclusion criteria with all the patients being operated by same surgeon at same institute using similar instrumentation in each case in both the groups. Also we strictly focus on polyethylene wear with stem as a variant in our study.

\section{Conclusion}

We found significant difference in polyethylene wear rates in Hybrid and Uncemented groups. But no significant difference found with respect to, clinical performance and revisions among the two groups of uncemented THA and hybrid THA when compared on a long term follow up basis. In our study we did not encounter any cases with definite implant loosening so the effect of polyethylene wear on implant loosening cannot be commented upon. More long term trials and complete year wise follow up data is required for further evaluation of the pattern of the polyethylene wear.

\section{References}

1. Lewallen DG, Cabanela ME (1996) Hybrid primary total hip arthroplasty: a 5- to 9-year followup study. Clin Orthop Relat Res (333): 126-133.

2. Wroblewski BM (1986) 15-21-year results of the Charnley low-friction arthroplasty. Clin Orthop Relat Res (211): 30-35.

3. Halley DK, Wroblewski BM (1986) Long-term results of low-friction arthroplasty in patients 30 years of age or younger. Clin Orthop Relat Res (211): 43-50.

4. Dumbleton JH, Manley MT, Edidin AA (2002) A literature review of the association between wear rate and osteolysis in total hip arthroplasty. J Arthroplasty 17(5): 649-661.

5. Harris WH (1994) Osteolysis and particle disease in hip replacement. A review. Acta Orthop Scand 65(1): 113-123.

6. Sochart DH (1999) Relationship of acetabular wear to osteolysis and loosening in total hip arthroplasty. Clin Orthop Relat Res (363): 135-150.

7. Sukur E, Akman YE, Ozturkmen Y, Kucukdurmaz F (2016) Particle Disease: A Current Review of the Biological Mechanisms in Periprosthetic Osteolysis After Hip Arthroplasty. Open Orthop J 10: 241-251.

8. Cooper RA, McAllister CM, Borden LS, Bauer TW (1992) Polyethylene debris-induced osteolysis and loosening in uncemented total hip arthroplasty. A cause of late failure. J Arthroplasty 7(3): 285-290.

9. Schmalzried TP, Jasty M, Harris WH (1992) Periprosthetic bone loss in total hip arthroplasty. Polyethylene wears debris and the concept of the effective joint space. J Bone Joint Surg Am 74(6): 849-863.

10. Dowd JE, Sychterz CJ, Young AM, Engh CA (2000) Characterization of long-term femoral-head-penetration rates. Association with and prediction of osteolysis. J Bone Joint Surg Am 82-A(8): 1102-1107.

11. Broomfield JA, Malak TT, Thomas GE, Palmer AJ, Taylor A, et al. (2016) The Relationship Between Polyethylene Wear and Periprosthetic Osteolysis in Total Hip Arthroplasty at 12 Years in a Randomized Controlled Trial Cohort. J Arthroplasty 32(4): 1186-1191. 
12. Parvizi J, Wade FA, Rapuri V, Springer BD, Berry DJ, et al. (2006) Revision hip arthroplasty for late instability secondary to polyethylene wear. Clin Orthop Relat Res 447: 66-69.

13. Kampa RJ, Hacker A, Griffiths E, Rosson JW (2010) In vivo polyethylene wear of bilateral total hip replacements - cemented versus uncemented modular sockets. Hip Int 20(4): 447-452.

14. Nashed RS, Becker DA, Gustilo RB (1995) Are cementless acetabular components the cause of excess wear and osteolysis in total hip arthroplasty? Clin Orthop Relat Res (317): 19-28.

15. Hartofilakidis G, Georgiades G, Babis GC (2009) A comparison of the outcome of cemented all-polyethylene and cementless metal-backed acetabular sockets in primary total hip arthroplasty. J Arthroplasty 24(2): 217-225.

16. Bjerkholt H, Hovik O, Reikeras O (2010) Direct comparison of polyethylene wear in cemented and uncemented acetabular cups. J Orthop Traumatol 11(3): 155-158.

17. Haw JG, Battenberg AK, Huang DT, Schmalzried TP (2017) Wear Rates of Larger-Diameter Cross-Linked Polyethylene at 5 to 13 Years: Does Liner Thickness or Component Position Matter? J Arthroplasty 32(4): 13811386.

18. Hagio K, Saito M, Okawa T, Moriyama S, Nakamura Y, et al. (2016) Polyethylene Wear Associated With 26-and 32-mm Heads in Total Hip Arthroplasty: A Multicenter, Prospective Study. Journal of Arthroplasty 31(12): 2805-2809.

19. Dorr LD, Faugere MC, Mackel AM, Gruen TA, Bognar B, et al. (1993) Structural and cellular assessment of bone quality of proximal femur. Bone 14(3): 231-242.

20. Gruen TA, McNeice GM, Amstutz HC (1979) Modes of failure of cemented stem-type femoral components: a radiographic analysis of loosening. Clin Orthop Relat Res (141): 17-27.

21. Barrack RL, Mulroy RD, Harris WH (1992) Improved cementing techniques and femoral component loosening in young patients with hip arthroplasty. A 12-year radiographic review. J Bone Joint Surg Br 74(3): 385-389.

22. Harris WH, McCarthy JC, O’Neill DA (1982) Femoral component loosening using contemporary techniques of femoral cement fixation. J Bone Joint Surg Am 64(7): 1063-1067.

23. Onsten I, Carlsson AS, Besjakov J (1998) Wear in uncemented porous and cemented polyethylene sockets: a randomised, radiostereometric study. J Bone Joint Surg Br 80(2): 345-350.

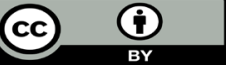

This work is licensed under Creative Commons Attribution 4.0 License

Submission Link: http://biomedres.us/submit-manuscript.php
24. Stambough JB, Pashos G, Bohnenkamp FC, Maloney WJ, Martell JM, et al. (2016) Long-Term Results of Total Hip Arthroplasty with 28-Millimeter Cobalt-Chromium Femoral Heads on Highly Cross-Linked Polyethylene in Patients 50 Years and Less. J Arthroplasty 31(1): 162-167.

25. Perez RE, Rodriguez JA, Deshmukh RG, Ranawat CS (1998) Polyethylene wear and periprosthetic osteolysis in metal-backed acetabular components with cylindrical liners. J Arthroplasty 13(1): 1-7.

26. Berger RA, Jacobs JJ, Quigley LR, Rosenberg AG, Galante JO (1997) Primary cementless acetabular reconstruction in patients younger than 50 years old - 7- to 11-year results. Clin Orthop Relat R (344): 216-226.

27. Poole CE, Patil SS, D Lima DD, Colwell CW (2005) Early follow-up for a hybrid total hip arthroplasty using a metal-backed acetabular component designed to reduce "backside" polyethylene wear. HSS J 1(1): 31-34.

28. Hernandez JR, Keating EM, Faris PM, Meding JB, Ritter MA (1994) Polyethylene wear in uncemented acetabular components. J Bone Joint Surg Br 76(2): 263-266.

29. Barrack RL, Folgueras A, Munn B, Tvetden D, Sharkey P (1997) Pelvic lysis and polyethylene wear at 5-8 years in an uncemented total hip. Clin Orthop Relat Res (335): 211-217.

30. Hooper GJ, Rothwell AG, Stringer M, Frampton C (2009) Revision following cemented and uncemented primary total hip replacement: a seven-year analysis from the New Zealand Joint Registry. J Bone Joint Surg Br 91(4): 451-458.

31. McMinn DJ, Snell KI, Daniel J, Treacy RB, Pynsent PB, et al. (2012) Mortality and implant revision rates of hip arthroplasty in patients with osteoarthritis: registry based cohort study. BMJ 344: 3319.

32. Clohisy JC, Harris WH (1999) Primary hybrid total hip replacement, performed with insertion of the acetabular component without cement and a precoat femoral component with cement. An average ten-year follow-up study. J Bone Joint Surg Am 81(2): 247-255.

33. Berger RA, Kull LR, Rosenberg AG, Galante JO (1996) Hybrid total hip arthroplasty: 7- to 10-year results. Clin Orthop Relat Res (333): 134-146.

34. Lewallen DG, Cabanela ME (1996) Hybrid primary total hip arthroplasty: a 5- to 9-year followup study. Clin Orthop Relat Res (333): 126-133.

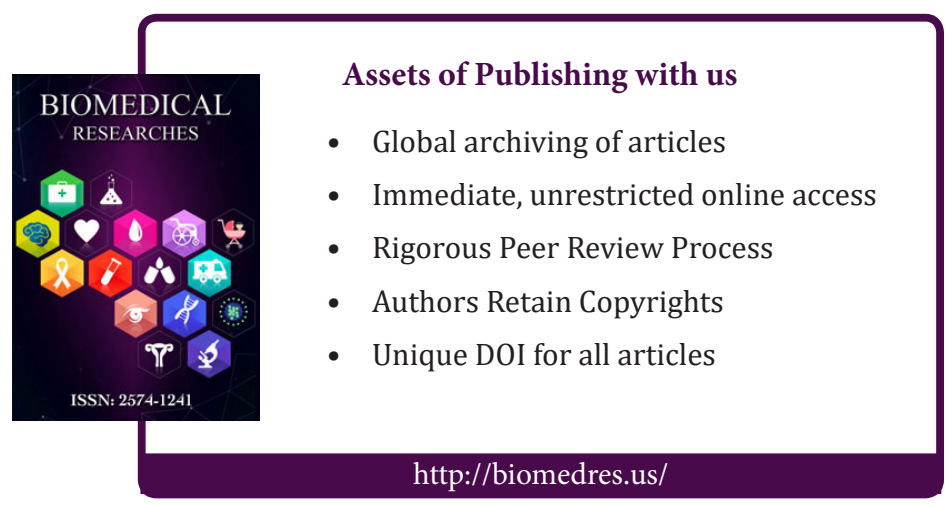

